\title{
Adherence to the GOLD Guideline in COPD Management of South Korea: Findings from KOCOSS Study 2011-2018
}

\author{
Tae-Ok Kim ${ }^{1}$, Hong-Joon Shin ${ }^{1}$, Yu-Il Kim ${ }^{1}$, Chin-Kook Rhee ${ }^{2}$, Won-Yeon Lee ${ }^{3}$, Seong-Yong Lim ${ }^{4}$, \\ Seung-Won Ra ${ }^{5}$, Ki-Suck Jung ${ }^{6}$, Kwang-Ha Yoo ${ }^{7}$, Seoung-Ju Park ${ }^{8}$, and Sung-Chul Lim ${ }^{1, *}$ \\ ${ }^{1}$ Division of Pulmonary Medicine, Department of Internal Medicine, Chonnam National University Hospital, Gwangju, Department of \\ Internal Medicine, ${ }^{2}$ The Catholic University of Korea, Seoul St. Mary's Hospital, Seoul, ${ }^{3}$ Yonsei University Wonju College of Medicine, Wonju, \\ Division of Pulmonary and Critical Care Medicine, ${ }^{4}$ Department of Medicine, Kangbuk Samsung Hospital, Sungkyunkwan University \\ School of Medicine, ${ }^{5}$ Department of Internal Medicine and the Clinical Research Center for Chronic Obstructive Airway Diseases, Asan \\ Medical Center, University of Ulsan College of Medicine, Seoul, ${ }^{6}$ Division of Pulmonary Medicine, Department of Internal Medicine, Hallym \\ University Sacred Heart Hospital, Hallym University Medical School, Anyang, ${ }^{7}$ Division of Pulmonary and Critical Care Medicine, \\ Department of Internal Medicine, Konkuk University Medical Center, Konkuk University School of Medicine, Seoul, ${ }^{8}$ Division of Pulmonary, \\ Allergy, and Critical Care Medicine, Department of Internal Medicine, Chonbuk National University Medical School, Jeonju, Korea
}

The guidelines for chronic obstructive pulmonary disease (COPD) treatment are important for the management of the disease. However, studies regarding the treatment adherence to the Global Initiative for Chronic Obstructive Lung Disease (GOLD) guidelines have been scarce in Korea. Therefore, to examine the adherence to the GOLD guidelines, we examined the patterns of prescribed medication in COPD patients from 2011 to 2018. Patients were classified as having been appropriately and inappropriately treated (overtreatment or undertreatment) for the GOLD group. Appropriate medical therapy was defined as using the first choice or alternative choice drug recommended in the GOLD guidelines. Inappropriate therapy was classified as overtreatment or undertreatment in accordance with the categorization in the GOLD guidelines. According to treatment of 2011 GOLD guidelines, there was inappropriate treatment in $52.3 \%$ in group A, $47.3 \%$ in group B, $56.3 \%$ in group C, and $17.8 \%$ in group D. According to treatment of 2017 GOLD guidelines, there was inappropriate treatment in $66.7 \%$ in group A, $45.3 \%$ in group B, $14.3 \%$ in group C, and $24.0 \%$ in group D. The common type of inappropriate COPD treatment is overtreatment, with inhaled corticosteroid (ICS) containing regimens. In conclusions, adherence to the GOLD guideline by the pulmonologist in clinical practice is still low in Korea. Therefore, we need better strategies to both optimize the use of the guidelines and adhere to the guidelines as well.

Key Words: Pulmonary Disease; Chronic Obstructive; Treatment Adherence

This is an Open Access article distributed under the terms of the Creative Commons Attribution Non-Commercial License (http://creativecommons.org/licenses/by-nc/4.0) which permits unrestricted non-commercial use,

distribution, and reproduction in any medium, provided the original work is properly cited.

\section{Article History:}

Received November 19, 2018

Revised December 6, 2018

Accepted December 10, 2018

\author{
Corresponding Author: \\ Sung-Chul Lim \\ Division of Pulmonary Medicine, \\ Department of Internal Medicine, \\ Chonnam National University Hospital, \\ 42 Jaebong-ro, Dong-gu, Gwangju \\ 61469 , Korea \\ Tel: +82-62-220-6570 \\ Fax: +82-62-225-8578 \\ E-mail: Iscmd@jnu.ac.kr
}

\section{INTRODUCTION}

Chronic obstructive pulmonary disease (COPD) is a major cause of chronic morbidity and mortality throughout the world. ${ }^{1}$ Several guidelines had been presented globally, among them the Global initiative for chronic obstructive lung disease (GOLD) guidelines is the most widely used and trusted clinical practice in the world. In the GOLD guidelines announced in 2011, patients with COPD were classified into 4 groups based on spirometric abnormality, exacerbation risk, and patient symptoms evaluated by COPD assessment test (CAT) or modified medical research council (mMRC). In 2017, new GOLD guidelines were classified into 4 groups based on the risk of exacerbations and patient's symptoms, with the exception of spirometric grading. ${ }^{1}$ The treatment protocols of GOLD guidelines recommended with $1^{\text {st }}$ and alternative choice drugs based on each group. $^{2}$

Appropriate treatment may reduce symptoms and the rate of exacerbations, thereby improving the quality of life, 
physical activity, as well as prolonging survival. ${ }^{1}$ GOLD guidelines are useful for the standardization of COPD pharmacological treatment. However, COPD treatment has not always been prescribed by pulmonologists according to GOLD guidelines. Turan et al. ${ }^{3}$ reported that the most common type of inappropriate COPD treatment is overtreatment, generally with inhaled corticosteroid (ICS). Some studies showed that $40-60 \%$ of patients had received appropriate treatment according to the GOLD guidelines. $^{3-6}$

The Korean COPD Subtype Study (KOCOSS) cohort was a large cohort which enrolled COPD patients from pulmonologists at 45 hospitals in South Korea. ${ }^{7}$ This cohort has registered patients since 2011 , and patients continue to register to this day. In the change of treatment paradigms for COPD, an understanding of how treatment practice by the pulmonologists in Korea continue to evolve is value in gauging the impact of treatment guidelines. However, studies regarding the treatment adherence to the GOLD guidelines have been scarce in Korea. Therefore, to examine the adherence to the GOLD guidelines, we examined the patterns of prescribed medication in Korean COPD patients from 2011 to 2018 using a KOCOSS cohort.

\section{MATERIALS AND METHODS}

\section{Study subjects}

All patients were selected from the KOCOSS cohort, which prospectively recruited patients from 45 referral hospitals in Korea between December 2011 and January 2018. Inclusion criteria were diagnosis of COPD by a pulmonologist, age $\geq 40$ years, symptoms including cough, sputum, dyspnea, and post-bronchodilator forced expiratory volume in one second $\left(\mathrm{FEV}_{1}\right) /$ forced vital capacity (FVC) of $70 \%$ less than normal predicted value. The medical history at the first visit included frequency and severity of exacerbations in the previous 12 months, smoking status, medications including those already prescribed for COPD, and comorbidities. The mMRC dyspnea score and
CAT were collected. A 6-minute walk distance (6MWD) test was also performed. All of the data was reported using case-report forms (CRFs) completed by physicians or trained nurses, and patients were to be evaluated at regular 6-month intervals after the initial examination. Major exclusion criteria were asthma, other obstructive lung diseases including bronchiectasis, tuberculosis destroyed lung, inability to complete pulmonary function test, myocardial infarction or cerebrovascular events within the previous 3 months, pregnancy, rheumatoid disease, malignancy, irritable bowel disease, and steroid use for conditions other than COPD exacerbation within the 8 weeks before enrollment. Exacerbations were defined as worsening of any respiratory symptom, such as increased sputum volume, purulence, or increased dyspnea, which required treatment with systemic corticosteroids, antibiotics, or both.

The patients who enrolled the KOCCOS cohort before 2017 were assigned a GOLD categorization of A, B, C or D based on 2011 guidelines. The patients who enrolled in the KOCCOS cohort after 2017 were assigned GOLD categorization based on 2017 guidelines.

The study protocol was approved by the Institutional Review Board of the Chonnam National University Hospital (CNUH 2012-070).

\section{Adherence to the GOLD guidelines}

Patients were classified as appropriately treated or inappropriately treated (overtreatment or undertreatment) for the GOLD group. Appropriate medical therapy was defined as using the first-drug choice or the alternative choice recommended in the GOLD guidelines. Inappropriate therapy was classified as overtreatment or undertreatment in accordance with the categorization in the GOLD guidelines (Table 1). ${ }^{1-3}$

Undertreatment in accordance with 2011 GOLD guideline was defined as treatment with:

- Group A: no inhaler

- Group B: only short-acting bronchodilator

TABLE 1. Criteria of inappropriate treatment according to GOLD guidelines

\begin{tabular}{|c|c|c|c|c|}
\hline & \multicolumn{2}{|c|}{ Adherence to GOLD 2014} & \multicolumn{2}{|c|}{ Adherence to GOLD 2017} \\
\hline & Under-treatment & Over-treatment & Under-treatment & Over-treatment \\
\hline Group A & No using inhaler & $\begin{array}{l}\text { LABA+LAMA } \\
\text { ICS } \\
\mathrm{PDE}_{4} \text { inhibitor }\end{array}$ & No using inhaler & $\begin{array}{l}\text { LABA+LAMA } \\
\text { ICS } \\
\mathrm{PDE}_{4} \text { inhibitor }\end{array}$ \\
\hline Group B & $\begin{array}{l}\text { Only short acting } \\
\text { bronchodilator }\end{array}$ & $\begin{array}{l}\text { ICS } \\
\mathrm{PDE}_{4} \text { inhibior }\end{array}$ & $\begin{array}{l}\text { Only short acting } \\
\text { bronchodilator }\end{array}$ & $\begin{array}{l}\text { ICS } \\
\mathrm{PDE}_{4} \text { inhibior }\end{array}$ \\
\hline Group C & Only ICS or LABA & $\begin{array}{l}\text { ICS+LABA+LAMA } \\
\text { ICS+LAMA } \\
\text { ICS+PDE }_{4} \text { inhibitor }\end{array}$ & Only ICS or LABA & $\begin{array}{l}\text { ICS+LABA+LAMA } \\
\text { ICS+LAMA } \\
\text { ICS+PDE }_{4} \text { inhibitor }\end{array}$ \\
\hline Group D & $\begin{array}{l}\text { Only ICS or LABA } \\
\text { or ICS+LAMA }\end{array}$ & $\begin{array}{l}\text { ICS+LABA+LAMA+PDE } \\
\text { inhibitor }\end{array}$ & $\begin{array}{l}\text { Only ICS or LABA } \\
\text { or ICS+LAMA }\end{array}$ & \\
\hline
\end{tabular}

GOLD: global initiative for chronic obstructive lung disease, LABA: long acting beta agonist, LAMA: long acting anticholinergics, ICS: inhaled corticosteroids, $\mathrm{PDE}_{4}$ : phosphodiesterase 4 . 
- Group C: only ICS or long-acting beta agonist (LABA)

- Group D: only ICS or LABA, ICS+Long-acting anticholinergics (LAMA)

Overtreatment in accordance with 2011 GOLD guideline was defined as treatment with:

- Group A: LABA+LAMA, ICS containing regimen, phosphodiesterase $4\left(\mathrm{PDE}_{4}\right)$ inhibitor

- Group B: ICS containing regimen, $\mathrm{PDE}_{4}$ inhibitor

- Group C: ICS+LABA+LAMA, ICS+LAMA, ICS+PDE 4 inhibitor

- Group D: ICS+LABA+LAMA+PDE 4 inhibitor

Undertreatment in accordance with 2017 GOLD guide-

line was defined as treatment with:

- Group A: no inhaler

- Group B: only short-acting bronchodilator

- Group C: only ICS or LABA

- Group D: only ICS or LABA, ICS+LAMA

Overtreatment in accordance with 2017 GOLD guide-

line was defined as treatment with:

- Group A: LABA+LAMA, ICS containing regimen, $\mathrm{PDE}_{4}$ inhibitor

- Group B: ICS containing regimen, $\mathrm{PDE}_{4}$ inhibitor

- Group C: ICS+LABA+LAMA, ICS+LAMA, ICS+PDE 4 inhibitor

\section{Statistical analysis}

All data is expressed as means and standard deviation (SD) or as numbers (percentages) in the text and tables. Intergroup comparisons were performed using the independent t-test for continuous variables following a normal distribution, and the Wilcoxon rank sum test for continuous variables not following a normal distribution and Pearson's $\chi^{2}$ test or Fisher's exact test for categorical variables. The level of significance was set at $p<0.05$. The data was analyzed using SPSS for Windows version 23.0 (SPSS Inc., Chicago, IL).

\section{RESULTS}

\section{Baseline patients characteristics}

Table 2 shows the baseline characteristics of the COPD patients for assessment of adherence to the GOLD guidelines. Among the 1818 patients with COPD, 1411 were selected from the KOCCOS cohort before 2017 and 407 were selected from the KOCCOS cohort after 2017. There was no difference in the mean age, sex and smoking status between the two patient groups. Their mean age was $69.2 \pm 7.9$ and $68.7 \pm 8.3$ years, respectively. Most of them were male $\left(91.8 \%, 94.5 \%\right.$, respectively). The mean $\mathrm{FEV}_{1}$ value was significantly lower in patients with enrollment before 2017 than patients with enrollment after 2017 $(59.9 \pm 18.9 \%$ predicted vs. $65.5 \pm 19.3 \%$ predicted, respectively, $\mathrm{p}<0.0001)$. The mean mMRC scores and CAT scores were worse in patients with enrollment before 2017. Exacerbation history was more prevalent in patients with enrollment before 2017 ( $26.0 \%$ vs. $13.0 \%$, respectively, $\mathrm{p}<0.0001)$. The most common comorbidities were hyper-
TABLE 2. Baseline characteristics

\begin{tabular}{|c|c|c|c|}
\hline & $\begin{array}{l}2011 \text { GOLD } \\
\text { guideline } \\
(\mathrm{n}=1411)\end{array}$ & $\begin{array}{l}2017 \text { GOLD } \\
\text { guideline } \\
(\mathrm{n}=407)\end{array}$ & $\mathrm{p}$-value \\
\hline Age, mean (SD) & $69.2 \pm 7.9$ & $68.7 \pm 8.3$ & 0.2609 \\
\hline Sex-male, n (\%) & $1273(91.8)$ & $380(94.5)$ & 0.0673 \\
\hline \multicolumn{4}{|l|}{ Smoking history, n (\%) } \\
\hline Current smoker & $368(26.2)$ & $104(26.3)$ & 0.5147 \\
\hline Ex-smoker & $918(65.3)$ & $265(67.0)$ & \\
\hline Never smoker & $121(8.6)$ & $27(6.8)$ & \\
\hline BMI, mean (SD) & $23.0 \pm 9.5$ & $23.2 \pm 3.2$ & 0.4839 \\
\hline \multicolumn{4}{|l|}{ Co-morbidity, n (\%) } \\
\hline Hypertension & $557(39.6)$ & $162(40.4)$ & 0.7775 \\
\hline Diabetes & $230(16.4)$ & $71(17.6)$ & 0.563 \\
\hline Coronary heart disease & $70(5.0)$ & $23(5.7)$ & 0.5491 \\
\hline Cerebrovascular disease & $33(2.4)$ & $6(1.5)$ & 0.2987 \\
\hline Congestive heart disease & $10(2.5)$ & $10(2.5)$ & 0.3581 \\
\hline $\mathrm{FEV}_{1}$, post $\mathrm{BD}(\mathrm{L})$, mean $(\mathrm{SD})$ & $1.60 \pm 0.60$ & $1.84 \pm 0.63$ & $<0.001$ \\
\hline $\mathrm{FEV}_{1}$, post $\mathrm{BD}(\%)$, mean $(\mathrm{SD})$ & $59.9 \pm 18.9$ & $65.5 \pm 19.3$ & $<0.001$ \\
\hline FEV1/FVC, mean (SD) & $55.2 \pm 17.8$ & $53.2 \pm 12.5$ & 0.6759 \\
\hline Exacerbation history, n (\%) & $363(26.0)$ & $52(13.0)$ & $<0.001$ \\
\hline \multicolumn{4}{|l|}{ GOLD group, $\mathrm{n}(\%)$} \\
\hline A & $239(16.9)$ & $132(32.4)$ & $<0.001$ \\
\hline $\mathrm{B}$ & $617(43.7)$ & $243(59.7)$ & \\
\hline $\mathrm{C}$ & $71(5.1)$ & $7(1.7)$ & \\
\hline $\mathrm{D}$ & $484(34.3)$ & $25(6.2)$ & \\
\hline mMRC score & $1.4 \pm 0.9$ & $1.2 \pm 0.9$ & $<0.001$ \\
\hline CAT score & $15.2 \pm 7.9$ & $12.8 \pm 7.9$ & $<0.001$ \\
\hline
\end{tabular}

$\mathrm{FEV}_{1}$ : forced expiratory volume in 1 second, FVC: forced vital capacity, GOLD: global initiative for chronic obstructive lung disease, mMRC: modified medical research council, CAT: chronic obstructive pulmonary disease assessment test.

tension and diabetes, which were independent of the timing of enrollment.

For patients enrolled after 2017 as compared to patients enrolled before 2017, the proportion of patients with group A and B increased while the group C and D decreased. Combinations of ICS, LABA and LAMA were the most common inhalers in patients with COPD before enrolled 2017. However, combinations of LABA and LAMA were the most common bronchodilators in patients with enrollment after 2017 (Table 3). The use of ICS containing regimens was reduced in patients enrolled after 2017 (43.9\% vs. 32.6\%).

\section{Adherence to the GOLD 2011 Guidelines}

When patients were classified according to the treatment guidelines, $61.5 \%$ of the patients were in the appropriately treated group (Table 4). There was no difference in mean age, sex, and smoking status between the appropriately treated patients and inappropriately treated patients. Appropriately treated patients had significantly lower post-bronchodilator FEV1 \% (56.7 \pm 17.5 vs. $65.0 \pm$ $20.0, \mathrm{p}<0.001)$, higher $\mathrm{mMRC}(1.5 \pm 0.9$ vs. $1.3 \pm 0.9, \mathrm{p}<0.001)$ and CAT scores $(15.7 \pm 7.7$ vs. $14.5 \pm 8.2, \mathrm{p}=0.007)$ and more exacerbation history ( $30.9 \%$ vs. $18.0 \%$ ) compared to patients in the inappropriately treated group. 
TABLE 3. Pharmarcologic regimens

\begin{tabular}{lccr}
\hline & $\begin{array}{c}\text { 2011 GOLD } \\
\text { guideline } \\
(\mathrm{n}=1411)\end{array}$ & $\begin{array}{c}\text { 2017 GOLD } \\
\text { guideline } \\
(\mathrm{n}=407)\end{array}$ & p-value \\
& $115(8.1)$ & $24(5.8)$ & 0.083 \\
No inhaler & $8(0.6)$ & $10(2.5)$ & 0.002 \\
SABA & $3(0.2)$ & $0(0.0)$ & 1.000 \\
SAMA & $138(9.9)$ & $28(6.9)$ & 0.074 \\
LABA & $346(24.5)$ & $83(20.4)$ & 0.079 \\
LAMA & $0(0.0)$ & $1(0.2)$ & 0.224 \\
ICS & $1(0.1)$ & $2(0.5)$ & 0.128 \\
Roflumilast & $146(10.3)$ & $107(26.3)$ & $<0.001$ \\
LABA+LAMA & $213(15.0)$ & $48(11.8)$ & 0.108 \\
ICS+LABA & $3(0.2)$ & $1(0.2)$ & 1.000 \\
ICS+LAMA & $363(25.6)$ & $70(17.2)$ & $<0.001$ \\
ICS+LABA+LAMA & $8(0.6)$ & $4(1.0)$ & 0.319 \\
LABA+Roflumilast & $12(0.9)$ & $5(1.2)$ & 0.557 \\
LAMA+Roflumilast & $1(0.1)$ & $0(0.0)$ & 1.000 \\
ICS+Roflumilast & $12(0.9)$ & $11(2.8)$ & 0.009 \\
LABA+LAMA+Roflumilast & $5(0.4)$ & $3(0.7)$ & 0.389 \\
ICS+LABA+Roflumilast & $37(2.6)$ & $10(2.5)$ & 1.000 \\
ICS+LABA+LAMA+ & & & \\
Roflumilast & & & \\
\hline GOLD+ globat initiative for & & &
\end{tabular}

GOLD: global initiative for chronic obstructive lung disease, SABA: short acting beta agonist, SAMA: short acting muscarinic antagonist, LABA; long acting beta agonist, LAMA: long acting muscarinic antagonist, ICS: inhaled corticosteroid.

TABLE 4. Comparisons to the adherence to the 2011 COPD guidelines

\begin{tabular}{lccr}
\hline & Appropriate & Inappropriate & \\
& $(\mathrm{n}=868)$ & $(\mathrm{n}=543)$ & -value \\
\hline Age, mean (SD) & $69.0 \pm 8.0$ & $69.4 \pm 7.8$ & 0.322 \\
Sex-male, n (\%) & $789(92.4)$ & $484(90.8)$ & 0.297 \\
Smoking status, n (\%) & & & 0.242 \\
$\quad$ Current smoker & $221(25.5)$ & $147(27.1)$ & \\
Ex-smoker & $576(66.7)$ & $342(63.0)$ & \\
$\quad$ Never smoker & $67(7.8)$ & $54(9.9)$ & \\
BMI, mean (SD) & $22.6 \pm 3.3$ & $23.7 \pm 14.6$ & 0.088 \\
FEV, post BD (L), mean (SD) & $1.54 \pm 0.55$ & $1.69 \pm 0.65$ & $<0.001$ \\
FEV, post BD (\%), mean (SD) & $56.7 \pm 17.5$ & $65.0 \pm 20.0$ & $<0.001$ \\
FEV1/FVC, mean (SD) & $49.5 \pm 12.7$ & $64.2 \pm 28.7$ & 0.236 \\
Exacerbation history, n (\%) & $266(30.9)$ & $97(18.0)$ & $<0.001$ \\
GOLD group, n (\%) & & & $<0.001$ \\
$\quad$ A & $114(13.1)$ & $125(23.4)$ & \\
B & $325(37.4)$ & $292(53.8)$ & \\
C & $31(3.6)$ & $40(7.4)$ & \\
D & $398(45.9)$ & $86(15.4)$ & \\
mMRC grade & $1.5 \pm 0.9$ & $1.3 \pm 0.9$ & $<0.001$ \\
CAT score & $15.7 \pm 7.7$ & $14.5 \pm 8.2$ & 0.007 \\
\hline
\end{tabular}

COPD: Chronic obstructive pulmonary disease, BMI: body mass index, $\mathrm{FEV}_{1}$ : forced expiratory volume in 1 second, $\mathrm{BD}$ : bronchodilator, FVC: forced vital capacity, GOLD: global initiative for chronic obstructive lung disease, mMRC: modified medical research council, CAT: chronic obstructive pulmonary disease assessment test.

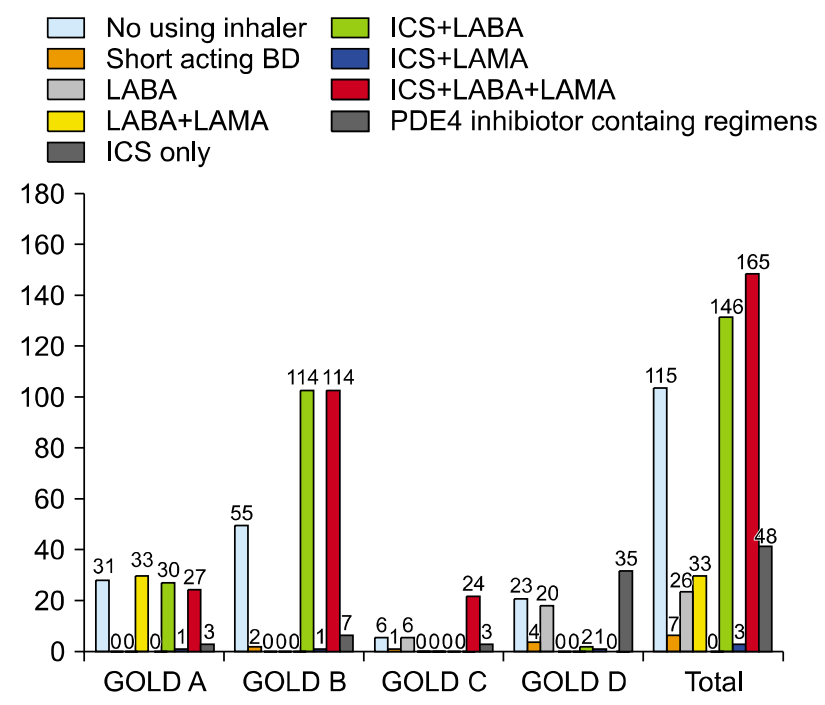

FIG. 1. Inappropriate treatment according to GOLD guideline published in 2011. GOLD: Global initiative for chronic obstructive lung disease, BD: bronchodilator, LABA: long acting beta2 agonist, ICS: inhaled corticosteroids, LAMA: long acting anticholinergics.

According to treatment using the GOLD guidelines, there was inappropriate treatment in $52.3 \%$ in group A, $47.3 \%$ in group B, $56.3 \%$ in group C, and $17.8 \%$ in group D. Of these inappropriate prescriptions, $395(72.7 \%)$ were overtreatment and $148(27.3 \%)$ were undertreatment. The most commonly prescribed medicine in patients who were treated inappropriately was ICS containing regimens (Fig. 1).

\section{Adherence of GOLD 2017 Guidelines}

According to the treatment by the GOLD guidelines, $49.6 \%$ of the patients were in the appropriately treated group (Table 5). Appropriately treated patients had significantly higher post-bronchodilator FEV1\% $(68.2 \pm 19.2$ vs. $62.8 \pm 19.2$, $\mathrm{p}=0.005)$, higher $\mathrm{mMRC}(1.4$ vs. $1.2, \mathrm{p}<0.001)$ and CAT scores (15.2 vs. $12.8, \mathrm{p}<0.001)$ and more exacerbation history ( $16.7 \%$ vs. $9.4 \%$ ) compared to patients in the inappropriately treated group. According to treatment using the GOLD guidelines, there was inappropriate treatment in $66.7 \%$ of group A, $45.3 \%$ of group B, $14.3 \%$ of group $\mathrm{C}$, and $24.0 \%$ of group D. Of these inapproropiate prescriptions, 175 (85.4\%)\% were overtreatment and 30 (14.6\%) were undertreatment. Of all those inappropriately treated, $45.5 \%$ received an ICS containing regimen and $37.5 \%$ LABA+LAMA in group A (Fig. 2).

\section{DISCUSSION}

Our result shows a low rate of adherence $(61.5 \%$ for 2011 , $49.6 \%$ for 2017 guideline) to GOLD guideline for treatment of COPD patients, which has also found similar results in several studies. ${ }^{3-5,8}$ White et al. ${ }^{9}$ demonstrated that only $58.1 \%$ of patients had received appropriate treatment according to GOLD guidelines. A Turkish study showed that 
TABLE 5. Comparisons to the adherence to the 2017 COPD guidelines

\begin{tabular}{lccc}
\hline & Appropriate & Inappropriate & \\
& $(\mathrm{n}=202)$ & $(\mathrm{n}=205)$ & $\mathrm{p}$-value \\
\hline Age, mean (SD) & $68.5 \pm 8.7$ & $68.7 \pm 7.9$ & 0.793 \\
Sex-male, n (\%) & $185(92.0)$ & $195(97.0)$ & 0.028 \\
Smoking status, n (\%) & & & 0.865 \\
$\quad$ Current smoker & $53(27.2)$ & $51(25.3)$ & \\
$\quad$ Ex-smoker & $128(65.6)$ & $137(68.2)$ & \\
$\quad$ Never smoker & $14(7.2)$ & $13(6.5)$ & \\
BMI, mean (SD) & $23.1 \pm 3.2$ & $23.3 \pm 3.3$ & 0.590 \\
FEV, post BD (L), mean (SD) $1.92 \pm 0.64$ & $1.76 \pm 0.61$ & 0.008 \\
FEV, post BD (\%), mean (SD) & $68.2 \pm 19.2$ & $62.8 \pm 19.2$ & 0.005 \\
FEV 1 FVC & $54.7 \pm 12.2$ & $51.6 \pm 12.6$ & 0.011 \\
Exacerbation history, n (\%) & $33(16.7)$ & $19(9.4)$ & 0.029 \\
GOLD group, n (\%) & & & $<0.001$ \\
A & $44(21.8)$ & $88(42.9)$ & \\
B & $133(65.8)$ & $110(53.7)$ & \\
C & $6(3.0)$ & $1(0.5)$ & \\
D & $19(9.4)$ & $6(2.9)$ & \\
mMRC score, mean (SD) & $1.3 \pm 0.9$ & $1.1 \pm 0.9$ & 0.073 \\
CAT score, mean (SD) & $13.8 \pm 8.0$ & $11.8 \pm 7.7$ & 0.013 \\
\hline
\end{tabular}

COPD: Chronic obstructive pulmonary disease, BMI: body mass index, $\mathrm{FEV}_{1}$ : forced expiratory volume in 1 second, $\mathrm{BD}$ : bronchodilator, FVC: forced vital capacity, GOLD: global initiative for chronic obstructive lung disease, mMRC: modified medical research council, CAT: chronic obstructive pulmonary disease assessment test.

only $40.4 \%$ of COPD patients received GOLD guidelineconcordant treatments. ${ }^{3}$ In previous studies, the researchers suggested that preference of devices, inadequate symptom evaluation, carelessness of pulmonologists, and hopes for steroid effectiveness were associated with low adherence to the GOLD guidelines. ${ }^{3,6,9}$

The GOLD guidelines are the most widely used medical guidelines for diagnosis and treatment of COPD in the world. The 2017 GOLD guidelines are classified into 4 groups based on risk of exacerbations and patient's symptoms, except for spirometric grading. ${ }^{1}$ Therefore, some of the patients who were in GOLD groups $\mathrm{C}$ and $\mathrm{D}$ in the 2011 GOLD guideline were reclassified to GOLD groups A and $\mathrm{B}$ in the 2017 GOLD guidelines. Patients whose groups were changed had to change treatment regimens. Appropriate treatment can reduce symptoms and the rate of exacerbations, thereby improving quality of life, physical activity, as well as prolonging survival. Therefore, it is necessary to identify the adherence to guidelines. To our knowledge, this is the first study of the adherence to the guidelines in Korea.

In our study, the adherence to the 2017 GOLD guidelines was $49.6 \%$. This was lower than adherence to the 2011 GOLD guidelines. This may be due to the fact that guidelines for the treatment of COPD in Korea still use postbronchodilator $\mathrm{FEV}_{1}$ as a basis for classifying patients into groups. ${ }^{10}$ In the Korean COPD guidelines, if $\mathrm{FEV}_{1}$ is less than $60 \%$, it is recommended that treatment correspond to

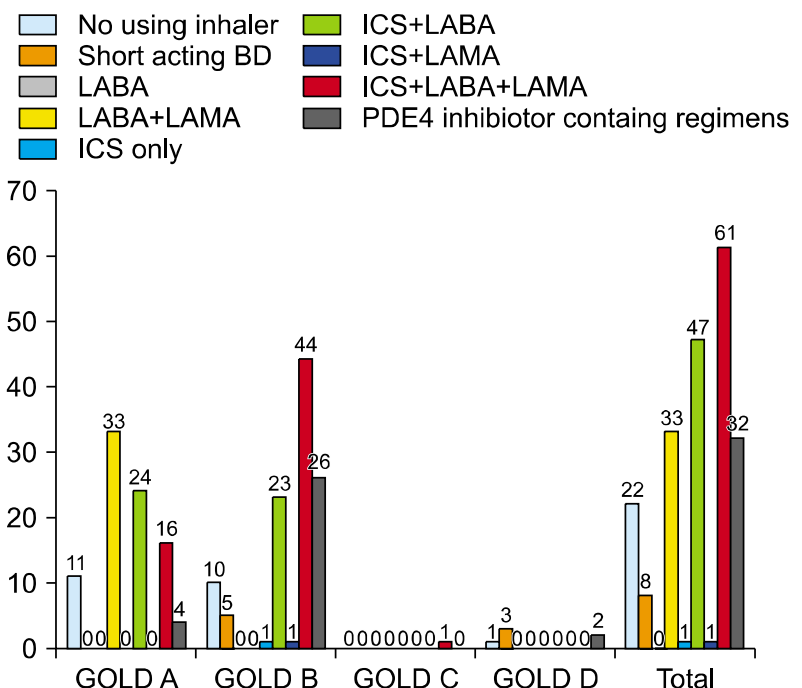

FIG. 2. Inappropriate treatment according to GOLD guideline published in 2017. GOLD: Global initiative for chronic obstructive lung disease, BD: bronchodilator, LABA: long acting beta2 agonist, ICS: inhaled corticosteroids, LAMA: long acting anticholinergics.

GOLD group D. Therefore, the two guidelines could be mixed and used in real practice. Another reason may be that there are still patients who are treated in a manner consistent with the 2011 GOLD guidelines. In our analysis, among the patients who changed from $\mathrm{D}$ to $\mathrm{B}$ in the 2017 GOLD guidelines, $54.1 \%$ received treatment with consistent 2011 GOLD guidelines.

In our study, patients who had high $\mathrm{FEV}_{1}$, less symptoms and a low incidence of exacerbation history were treated inappropriately based on the 2011 GOLD guidelines. A Turkish study showed that, according to the spirometric classification, there was inappropriate treatment in $95.6 \%$ in stage I, $69.7 \%$ in stage II, $4.9 \%$ in stage III, and $14.3 \%$ in stage IV. Of these inappropriate prescriptions, $96.2 \%$ were overtreatment. ${ }^{3}$ Patients who were inappropriately treated based on the 2017 GOLD guidelines had a lower history of exacerbation and fewer symptoms, but had a lower FEV1 unlike the patients who received treatment inconsistent 2011 GOLD guidelines.

Our study shows that there was inappropriate treatment in $52.3 \%$ of group A, $47.3 \%$ of group B, $56.3 \%$ of group $\mathrm{C}$, and $17.8 \%$ of group $\mathrm{D}$, which has also been reported in other studies. ${ }^{3,6,8,9}$ Turan et al. ${ }^{3}$ demonstrated that $64 \%$ of patients in group A, $70 \%$ in group B, and $53 \%$ in group $\mathrm{C}$ were using unsuitable treatment for COPD. Another study showed that patients in groups $\mathrm{B}$ and $\mathrm{C}$ were most often treated inappropriately within the GOLD guidelines. ${ }^{8}$ In most studies, including our study, the GOLD group D most commonly received treatment consistent with the GOLD guidelines. ${ }^{3,6,8,9}$ These results suggested that the complexity of GOLD assessment could influence the outcomes of previous studies. In addition, the GOLD guidelines are not recommend for ICS containing regimens for GOLD group $\mathrm{A}$ and $\mathrm{B}$, one of the most commonly prescribed medicines 
in patients with COPD.

Patients registered after 2017 increased the combined use of LABA and LAMA and ICS, LABA and LAMA, and decreased the combined use of ICS and LABA concurrently, compared with patients enrolled before 2017. This change is because the combination of LABA and LAMA is effective in improving lung function, symptoms, and quality of life and reducing exacerbation compared to LAMA ${ }^{11}$ or a combination of ICS and LABA. ${ }^{12}$ ICS has several side effects, among them is an increased incidence of pneumonia which is the most important side effect in patients with COPD. It was also known that the incidence of osteoporosis, cataracts, and diabetes increased as well. Nevertheless, a prescription containing ICS regimens was most inappropriately prescribed relative to the GOLD guidelines in patients with COPD. In our study, inappropriately prescribed drugs in the GOLD guidelines were generally ICS containing regimens. Of the patients who were improperly treated based on the 2011 GOLD guidelines, $45.6 \%$ of Group A and 69.8\% of Group B received a prescription containing ICS. In the cases of patients with treatment inconsistent with 2017 GOLD guidelines, $45.5 \%$ of Group A and $62.8 \%$ of Group B were prescribed ICS containing regimens. In several studies, ${ }^{3,13-15}$ ICS was the most common medication to receive treatment inconsistent with the GOLD guidelines. For these possible reasons, there have been reports that combination therapy with ICS and LABA improves symptoms and reduces acute exacerbations and improves quality of life in patients with $\mathrm{COPD}^{13-15}$ and that ICS has been frequently prescribed at every stage of COPD. ${ }^{16,17}$ There have also been several studies in which ICS has been shown to be effective in the treatment of blood eosinophilia $^{18,19}$ and asthma COPD overlap. ${ }^{20}$

There are some limitations in our study. First, patients who registered after 2017 had more GOLD group A members than other cohort studies. Second, patients who started treatment before 2017 were still being treated with the 2011 guidelines, even though the guidelines were revised in 2017. These patients may have affected the adherence to the GOLD guidelines. Finally, there was no data on the cause of the prescription for ICS-containing regimens in this study.

In conclusion, our study demonstrates that adherence to the GOLD guidelines by pulmonologists in clinical practice is still low. ICS containing regimens are the most commonly received medication in patients inconsistent with the GOLD guidelines. Therefore, we need a better strategy to optimize the use of these guidelines and increase adherence to the guidelines.

\section{ACKNOWLEDGEMENTS}

This research was supported by a fund (2016ER670102 \& 2018ER670100) by Research of Korea Centers for Disease Control and Prevention.

\section{CONFLICT OF INTEREST STATEMENT}

None declared.

\section{REFERENCES}

1. Vogelmeier CF, Criner GJ, Martinez FJ, Anzueto A, Barnes PJ, Bourbeau J, et al. Global strategy for the diagnosis, management, and prevention of chronic obstructive lung disease 2017 report. GOLD executive summary. Am J Respir Crit Care Med 2017;195: $557-82$.

2. Vestbo J, Hurd SS, Agustí AG, Jones PW, Vogelmeier C, Anzueto A, et al. Global strategy for the diagnosis, management, and prevention of chronic obstructive pulmonary disease: GOLD executive summary. Am J Respir Crit Care Med 2013;187:347-65.

3. Turan O, Emre JC, Deniz S, Baysak A, Turan PA, Mirici A. Adherence to current COPD guidelines in Turkey. Expert Opin Pharmacother 2016;17:153-8.

4. Palmiotti GA, Lacedonia D, Liotino V, Schino P, Satriano F, Di Napoli PL, et al. Adherence to GOLD guidelines in real-life COPD management in the Puglia region of Italy. Int J Chron Obstruct Pulmon Dis 2018;13:2455-62.

5. Jochmann A, Scherr A, Jochmann DC, Miedinger D, Török SS, Chhajed PN, et al. Impact of adherence to the GOLD guidelines on symptom prevalence, lung function decline and exacerbation rate in the Swiss COPD cohort. Swiss Med Wkly 2012;142: w13567.

6. Chan KP, Ko FW, Chan HS, Wong ML, Mok TY, Choo KL, et al. Adherence to a COPD treatment guideline among patients in Hong Kong. Int J Chron Obstruct Pulmon Dis 2017;12:3371-9.

7. Lee JY, Chon GR, Rhee CK, Kim DK, Yoon HK, Lee JH, et al. Characteristics of patients with chronic obstructive pulmonary disease at the first visit to a pulmonary medical center in Korea: the Korea COPD Subgroup Study Team Cohort. J Korean Med Sci 2016;31:553-60.

8. Ghosh S, Anderson WH, Putcha N, Han MK, Curtis JL, Criner GJ, et al. Alignment of inhaled COPD therapies with published strategies: analysis of the GOLD recommendations in SPIROMICS. Ann Am Thorac Soc 2018. doi: 10.1513/AnnalsATS. 201804-283OC. [Epub ahead of print]

9. White P, Thornton H, Pinnock H, Georgopoulou S, Booth HP. Overtreatment of COPD with inhaled corticosteroids--implications for safety and costs: cross-sectional observational study. PLoS One 2013;8:e75221.

10. Park YB, Rhee CK, Yoon HK, Oh YM, Lim SY, Lee JH, et al. Revised (2018) COPD clinical practice guideline of the Korean Academy of Tuberculosis and Respiratory Disease: a summary. Tuberc Respir Dis (Seoul) 2018;81:261-73.

11. Calzetta L, Rogliani P, Matera MG, Cazzola M. A systematic review with meta-analysis of dual bronchodilation with LAMA/LABA for the treatment of stable COPD. Chest 2016;149: 1181-96.

12. Wedzicha JA, Banerji D, Chapman KR, Vestbo J, Roche N, Ayers $\mathrm{RT}$, et al. Indacaterol-glycopyrronium versus salmeterol-fluticasone for COPD. N Engl J Med 2016;374:2222-34.

13. Calverley PM, Anderson JA, Celli B, Ferguson GT, Jenkins C, Jones PW, et al. Salmeterol and fluticasone propionate and sur- 
vival in chronic obstructive pulmonary disease. N Engl J Med 2007;356:775-89.

14. Decramer ML, Chapman KR, Dahl R, Frith P, Devouassoux G, Fritscher C, et al. Once-daily indacaterol versus tiotropium for patients with severe chronic obstructive pulmonary disease (INVIGORATE): a randomised, blinded, parallel-group study. Lancet Respir Med 2013;1:524-33.

15. Wedzicha JA, Calverley PM, Seemungal TA, Hagan G, Ansari Z, Stockley RA. The prevention of chronic obstructive pulmonary disease exacerbations by salmeterol/fluticasone propionate or tiotropium bromide. Am J Respir Crit Care Med 2008;177:19-26.

16. Corrado A, Rossi A. How far is real life from COPD therapy guidelines? An Italian observational study. Respir Med 2012;106: 989-97.

17. Jebrak G. [COPD routine management in France: are guidelines used in clinical practice?]. Rev Mal Respir 2010;27:11-8. French. 18. Watz H, Tetzlaff K, Wouters EF, Kirsten A, Magnussen H, Rodriguez-Roisin R, et al. Blood eosinophil count and exacerbations in severe chronic obstructive pulmonary disease after withdrawal of inhaled corticosteroids: a post-hoc analysis of the WISDOM trial. Lancet Respir Med 2016;4:390-8.

19. Barnes NC, Sharma R, Lettis S, Calverley PM. Blood eosinophils as a marker of response to inhaled corticosteroids in COPD. Eur Respir J 2016;47:1374-82.

20. Plaza V, Álvarez F, Calle M, Casanova C, Cosío BG, López-Viña A, et al. Consensus on the Asthma-COPD Overlap (ACO) between the Spanish COPD Guidelines (GesEPOC) and the Spanish Guidelines on the Management of Asthma (GEMA). Arch Bronconeumol 2017;53:443-9. 